\title{
SENAM TAI CHI EFEKTIF MENURUNKAN \\ TEKANAN DARAH, KADAR GULA, DAN MENINGKATKAN KUALITAS TIDUR PADA LANSIA
}

\author{
Atika Yulianti*, Atika Suri, Afni Widadari Febilia, Reni Endah Herowati \\ Program Studi Fisioterapi, Fakultas Ilmu Kesehatan, Unversitas Muhammadiyah Malang \\ *Korespondensi :atika@umm.ac.id
}

\begin{abstract}
ABSTRAK
Lansia merupakan kondisi yang rentan terhadap stress yang diakibatkan dengan menurunnya kapasitas tubuh dan timbulnya berbagai penyakit degenerative antara lain seperti gangguan kualitas tidur, diabetes mellitus, hipertensi. Penurunan kualitas tidur sedikitnya disebabkan antara lain oleh disfungsi aktivitas pada siang hari, penurunan fungsi neurotransmitter sehingga neroepinephrine mengalami penurunan, sehingga menyebabkan mudahnya terbangun pada malam hari dan pola tidur dan istirahat berubah serta dapat mengganggu kualitas tidur lansia. Begitu juga pada gangguan kardiovaskular pada lansia, salah satunya hipertensi, gangguan ini disebabkan oleh pengkakuan pembuluh darah dan penurunan kelenturan (compliance) arteri dan ini mengakibatkan peningkatan tekanan nadi sesuai dengan umur. Perubahan ini menyebabkan penurunan compliance aorta dan pembuluh darah besar dan mengakibatkan peningkatan TDS yang menyebabkan hipertensi. Selain itu gangguan metabolic juga menjadi resiko besar yang sering terjadi pada lansia, khusunya tingginya kasus diabetes mellitus, yang merupakan akibat dari resistensi insulin cenderung meningkat pada usia lanjut sehingga dapat mempengaruhi peningkatan kadar glukosa darah. Semua keluhan degenatif yang disebutkan diatas berdampak pada penurunan kualitas hidup lansia. Obat obatan menjadi kebutuhan yang sangat tinggi untuk menanggulangi keluhan pada kondisi yang menua, padahal kondisi tubuh mereka sudah tidak terlalu baik untuk mensekresi obat, yang paling buruk efek konsumsi obat akan menimbulkan kelainan lain seperti gagal ginjal. Oleh karena itu pola fikir dan pola aktivitas lansia harus segera diperbaiki. Meningkatkan pola aktivitas sangat membantu untuk menurunkan keluahan keluhan tersebut. Pada penelitian ini digunkan senam tai chi sebagai peningkatan pola aktivitas pada lansia. Taichi sendiri dipilih karena gerakan yang aman digunakan para lanjut usia, selain itu efek terapi dari tai chi sendiri yaitu dapat menurunkan tekanan darah, menekan pengeluaran hormone hormone yang dapat meningkatkan kadar gula darah, dan menurunkan kadar kortisol dan menurunkan aktivits saraf simpatis sehingga dapat meningkatkan kualitas tidur pada lansia.
\end{abstract}

Kata Kunci: Tai Chi, Hipertensi, Diabetes Mellitus, Gangguan Kualitas Tidur.

\section{PENDAHULUAN}

Proses menua merupakan suatu kondisi yang wajar dan tidak dapat dihindari dalam fase kehidupan (Yulianti, 2014). Proses penuaan merupakan proses yang mengakibatkan perubahan-perubahan meliputi perubahan fisik, psikologis, sosia dan spiritual. Pada perubahan fisiologis terjadi penurunan sistem kekebalan tubuh dalam menghadapi gangguan dari dalam maupun luar tubuh.

Penyakit degeneratif merupakan pergeseran fenomena kesehatan antara jenis penyakit dari penyakit menular ke penyakit tidak menular. Dengan gaya hidup yang serba instan dan praktis masyarakat lebih banyak menderita penyakit degenerative seperti diabetes militus (Bustan, 2007). 
Diabetes melitus merupakan suatu penyakit yang diakibatkan karena tubuh penderitanya tidak bisa secara otomatis mengontrol kadar gula di dalam darah. Diabetes melitus merupakan penyakit silent killer yang ditandai dengan peningkatan kadar glukosa darah dan kegagalan sekresi insulin atau penggunaan insulin dalam metabolisme yang tidak adekuat (Sudoyo dkk, 2006).

Berdasarkan data yang diperoleh dari KEMENKES (2013) menunjukkan bahwa dari 10 penyakit tersering yang diderita kelompok lansia nampak jenis penyakit yang mendominasi adalah golongan penyakit yang tidak menular, penyakit kronik dan degeneratif, terutama golongan penyakit kardiovaskular. Hipertensi menjadi urutan pertama dengan prevalensi menurut kelompok umur 55-66 tahun (45.9\%), 65-74 tahun (57.6\%), dan 75 tahun keatas $(63.8 \%)$. Jauh lebih tinggi dibanding penyakit jantung koroner dengan prevalensi kelompok umur 55-66 tahun (2.8\%), 65-74 tahun (3.6\%), dan 75 tahun keatas $(3.2 \%)$.

Hipertensi di definisikan sebagai tekanan darah tinggi yang tidak normal (lebih dari 120/80 mmHg) di arteri. Faktor risiko dari penyakit hipertensi akan menyebabkan kerusakan organ tubuh seperti jantung, pembuluh darah, retina dan sistem saraf pusat. Hipertensi sering disebut "silent killer" karena umumnya tidak menunjukkan gejala sampai komplikasi serius yang berkembang (Siyad, 2011).

Pada serangkaian laporan lainya didapatkan keluhan lain yaitu ganggau pada tidur, dimana dilaporkan $50 \%$ dari orang tua menderita gangguan tidur. Hal ini juga menjelaskan bahwa hampir $80 \%$ dari usia 70 tahun ke atas pria dan wanita setidaknya menderita gangguan kronik yang membuat mereka rentan terkena gangguan tidur (Rezaei,et al,2010).

Penyebab dari gangguan tidur atau insomnia pada lansia adalah gangguan psikologi, stress, depresi, efek samping obat, penyakit-penyakit kronis yang diderita pasien. Apabila tidak segera dicegah maka akan terjadi insomnia kronik yang akan lebih mengakibatkan banyak masalah(Roth,2007). Keluhan lain dilaporkan antara lain penurunan kekuatan otot dan kelenturan sendi (Pudjiastuti \& Utomo, 2003).7

Beberapa langkah penting untuk menjadi lansia yang sehat dan sejahtera adalah dengan melaksanakan pola makan yang sehat, olahraga kesehatan yang adekuat (cukup) dan teratur, menghindari hal-hal buruk seperti merokok, minum alkohol juga menghindari zat-zat polutan berbahaya lainnya serta berusaha membebaskan diri dari berbagai gangguan/ beban mental psikologi, melalui berbagai kegiatan keagamaan dan sosial (bersosialisasi) dengan masyarakat lingkungan (Giriwijoyo \& Sidik, 2012).

Salah satu kegiatan olahraga atau senam yang bisa dilakukan pada lansia adalah senam Tai Chi (Adenikheir, 2014). Tai Chi merupakan latihan aerobik dengan gerakangerakan halus yang relatif lambat sehingga dikategorikan sebagai latihan yang bersifat low impact velocity dan merupakan bentuk latihan yang cocok untuk lansia. Selain itu latihan Tai Chi dapat meningkatkan kemampuan otot untuk mengkonsumsi oksigen secara maksimal. Hal ini terjadi karena luas permukaan difusi $\mathrm{O} 2$ di dalam otot meningkat sehingga difusi O2 dari kapiler ke otot menjadi lebih mudah, difusi $\mathrm{CO} 2$ dari kapiler ke otot menjadi lebih mudah dan metabolisme aerobik pembentukan energi dalam otot menjadi lebih baik. Selain itu membuat daya tahan jantung dan paru menjadi lebih baik karena terjadi peningkatan kapasitas paru-paru akibat gerakan Tai Chi yang lembut, terus menerus, disertai dengan penarikan dan penghembusan nafas yang panjang. Hal ini akan meningkatkan kemampuan otot-otot pernafasan, meningkatkan elastisitas rongga dada dan paru-paru, sehingga kemampuan mengembang paru-paru dan dinding dada meningkat pula (Adenikheir, 2014). Hal tersebut membuktikan senam tai chi yang bersifat aerobik low impact dan relaksasi 
berpengaruh terhadap perubahan penurunan kadar gula darah pada lansia potensi diabetes mellitus.

Efek dari senam tai chi lainya yaitu aktivitas dari saraf simpatis dan parasimpatis menjadi seimbang dan harmonis. Latihan tersebut dapatpula meningkatakan antioksidan untuk menghilangkan radikal bebas bebas dalam tubuh dan menstabilkan tekanan darah Sutanto (2013).

Aktivitas fisik membuat tubuh mengeluarkan hormon adrenalin, serotonin, dopamine dan endorphin yang bekerja untuk membuat tubuh menjadi lebih baik, endorphin merupakan penghilang rasa sakit alami pada tubuh yang dapat mengurangi stress dan meningkatkan suasana hati sehingga, pada saat tidur dimalam hari kualitas tidur akan meningkat (Yurintika et al. 2013).

\section{METODE PENELITIAN}

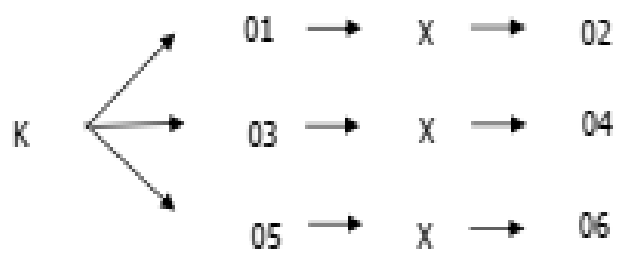

Gambar 1 Desain Penelitian (Data Primer, 2019)

Keterangan :

$\mathrm{K}$ : Subjek

$\mathrm{X}$ : Latihan Tai Chi

01 : Nilai Pretest tekanan darah (

02 : Nilai PostTest Tekanan Darah

03 : Nilai pretest Kadar Gula

04 : Nilai Postest Kadar Gula

05 : Nilai Pretest PSQI

06 : Nilai Pretest PSQI

Penelitian ini menggunakan pendekatan kuantitatif dengan jenis penelitian Quasi eksperimen dengan pre post test group design. Pada penelitian ini peneliti menggunakan 3 kelompok perlakuan dimana nantinya kelompok subjek ini akan mendapat 3 perlakuan dan pengguuran yang berbeda yang berbeda. Langkah pertama peneliti menentukan sampel berdasarkan populasi yang ditentukan dan melalui kriteria eksklusi dan inklusi. Langkah berikutnya pada tiap kelompok perlakuan dilakukan pengukuran awal disetiap kelompok. Kemudian sampel diberikan latihan senam tai chi. Pada minggu ke enam, dilakukan pengukuran akhir ditiap kelompok, alat ukur yang sama dengan pengukuran awal sebelum perlakuan di tiap kelompok yang berbeda.

Populasi dalam penelitian ini adalah Lansia yang bertempat tinggal disekitar wilayah Puskesmas Dinoyo Malang, Jawa Timur. Sampel dalam penelitian ini diambil berdasarkan dengan jumlah lansia yangmemenuhi kriteria inklusi di tiap kelompoknya. Penelitian dilakukan di Balai desa Junrejo Kota Batu. Penelitian ini akan dilaksanakan pada tanggal 1 Januari s/d 1 Juni 2017

\section{HASIL PENELITIAN}

\section{Karakteristik Sampel berdasarkan Usia}

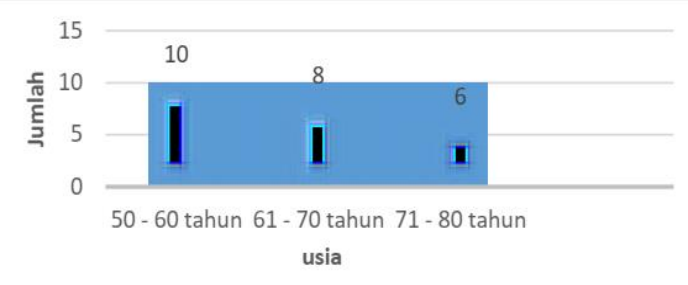

Gambar 2. Karakteristik sampel Berdasarkan Usia (Data primer, 2019)

Distribusi usia responden di posyandu lansia di desa junrejo kota Batu pada kelompok perlakuan dengan senam tai chi memiliki karakteristik usia dari 55 tahun sampai usia 67 tahun dengan rata-rata usia 61 tahun. Sedangkan pada kelompok kontrol memiliki karakteristik usia dari 54 tahun sampai usia 80 tahun dengan rata-rata 66 tahun. 
Karakteristik Sampel berdasarkan Pekerjaan

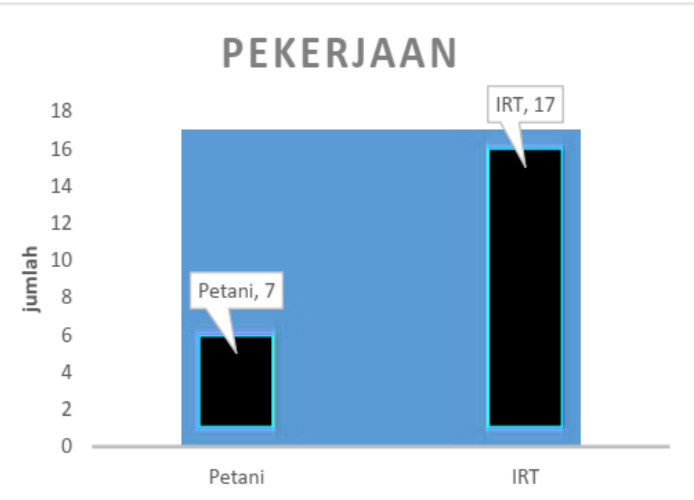

Gambar 3. Karakteristik Sampel berdasarkan Pekerjaan (Data Primer, 2019)

Distribusi pekerjaan responden di posyandu lansia di desa Junrejo kota Batu seluruh (100\%) kelompok perlakuan dengan senam tai chi bekerja sebagai ibu rumah tangga (IRT) $100 \%$, sedangkan pada kelompok control terdapat $7(58 \%)$ orang bekerja sebagai petani dan $5(42 \%)$ orang sebagai ibu rumah tangga (IRT)

\section{Hasil Perbandingan Nilai Tekanan Darah Sebelum dan Sesudah dibarikan TaiChi}

Table 1 Perbandingan Tekanan Darah Sebelum dan Sesudah kelompok ekperimen

\begin{tabular}{llll}
\hline & Sistol Pre & $\begin{array}{l}\text { Sistol } \\
\text { Post }\end{array}$ & Selisih \\
\hline Mean & 154,00 & 138,67 & 15,33 \\
\hline SD & 18,439 & 15,976 & 8,338 \\
\hline & $\begin{array}{l}\text { Diastol } \\
\text { Pre }\end{array}$ & $\begin{array}{l}\text { Diastol } \\
\text { Post }\end{array}$ & Selisih \\
\hline Mean & 83,33 & 80,00 & 3,33 \\
\hline SD & 9,759 & 9,258 & 8,165 \\
\hline
\end{tabular}

Hasil Perbandingan Nilai Kadar gula Darah Sebelum Dan Sesudah Pemberian Latihan Tai Chi

Tabel 2 Perbandingan Nilai Kadar Gula Darah Sebelum dan Sesudah kelompok ekperimen

\begin{tabular}{lllc}
\hline & Pre & Post & Selisih \\
\hline Mean & 260.4 & 157 & 103.4 \\
\hline $\begin{array}{l}\text { Standar } \\
\text { deviasi }\end{array}$ & 126.5 & 52.6 & 95.4 \\
\hline
\end{tabular}

Diterima : 06/08/2019 Direvisi : 02/09/2019 Disetujui : 13/10/2019

Hasil Perbandingan Nilai Kualitas Tidur Sebelum Dan Sesudah Pemberian Latihan Tai Chi

Tabel 3 Perbandingan Nilai Kualitas Tidur (PSQI) Sebelum dan Sesudah kelompok ekperimen

\begin{tabular}{llll}
\hline & Pre & Post & Selisih \\
\hline Mean & 13,3 & 11,4 & -2.4 \\
\hline SD & 1,2 & 0,9 & 1,4 \\
\hline
\end{tabular}

Uji pengaruh Pada Kelompok Tekanan Darah

\begin{tabular}{lll}
\multicolumn{3}{c}{ Table 4. Tabel Uji Normalitas } \\
\hline Kelompok & $\begin{array}{l}\text { Pre } \\
\text { Test }\end{array}$ & $\begin{array}{l}\text { Post } \\
\text { Test }\end{array}$ \\
\hline $\begin{array}{l}\text { Tekanan Darah } \\
\text { (Sistole) }\end{array}$ & 0,358 & 0,585 \\
$\begin{array}{l}\text { Tekanan Darah } \\
\text { (Diastole) }\end{array}$ & 0,386 & 0,354 \\
$\begin{array}{l}\text { Kadar gula Darah } \\
\text { Kulaitas Tidur }\end{array}$ & 0,141 & 0,939 \\
\hline
\end{tabular}

Dari table uji normalitas dengan menggunakan Uji Saphito Wilk Tes, didapatkan hasil bahwa seluruh data terdisteribusi normal

Tabel 5. Uji Paired t-test Pada kelompok Tekanan Darah

\begin{tabular}{ccc}
\hline Variabel & Pre-post & Sig. \\
\hline Sphygmomanometer & Sistol & 0,000 \\
One Med & Diastol & 0,136 \\
\hline
\end{tabular}

Tabel 5 diatas menunjukkan bahwa terdapat perbedaan yang signifikan pada kelompok ekperimen antara nilai sebelum dan sesudah tekanan darah sistol senam tai chi dengan nilai $\mathrm{Sig}=0,000$ pada $\alpha 0,05$ $($ Sig $<0,05)$ pada tekanan darah diastol tidak ada perbedaan signifikan nilai sebelum dan sesudah di berikan

\section{Uji Pengaruh Kelompok Gula Darah}

Tabel 6. Uji Paired t-test Pada kelompok Gula

\begin{tabular}{lll}
\multicolumn{2}{l}{ darah } \\
\hline Variable & Latihan TC & Sig. \\
\hline Kadar Gula Darah & Pre-post & 0,003 \\
\hline
\end{tabular}

Dari hasil uji peraruh dengan menggunakan uji pairet t-test di atas diatas 
menunjukkan ahwa kelompok perlakuan dengan senam tai chi terjadi perbedaaan atau penurunan nilai antara sebelum dan sesudah intervensi yang signifikan dengan nilai sig. $=0,003$ pada $\alpha 0,05(\mathrm{Sig}<0,05)$.

\section{Uji Pengaruh Kelompok Kualitas Tidur}

Tabel 7 Uji Paired t-test Pada kelompok Kualitas Tidur

\begin{tabular}{llll}
\hline Variable & Senam Tai Chi & Sig & a \\
\hline Kuisioner & Pre-post & 0.00 & 0.05 \\
PSQI & & & \\
\hline
\end{tabular}

Dari hasil uji pengaruh dengan menggunakan uji pairet t-test menunjukkan bahwa terdapat perbedaan yang signifikan antara nilai sebelum dan sesudah intervansi pada kelompok yang diberikan senam Tai Chi dengan nilai sig. $=0,000$ pada a 0,05 $($ Sig $<0,05)$ kesimpulannya adalah $\mathrm{H} 1$ diterima.

\section{PEMBAHASAN}

Menurut Syatria (2006) Saat melakukan aktivitas aerobik, tekanan darah akan meningkat cukup banyak misalnya, selama melakukan latihan-latihan aerobik dengan intensitas tinggi, tekanan darah sistol dapat naik menjadi 150 - $200 \mathrm{mmHg}$ dari tekanan darah sistol ketika istirahat sebesar 110 - 120 mmHg. Sebaliknya segera setelah latihan aerobik selesai, tekanan darah akan turun sampai di bawah normal dan berlangsung selama 30 - 120 menit. Apabila olahraga aerobik dilakukan berulang-ulang, lama-kelamaan penurunan tekanan darah akan berlangsung lebih lama, hal tersebut menyebabkan latihan olahraga secara teratur akan dapat menurunkan tekanan darah. Jenis olahraga yang efektif menurunkan tekanan darah adalah olahraga aerobik dengan intensitas sedang dengan frekuensi latihan 3 - 5 kali seminggu, lama latihan 20 - 60 menit sekali latihan.

Didukung oleh penelitian yang dilakukan oleh Nguyen \& Kruse (2012) dimana pada penelitian ini menunjukkan penurunan sistol yang signifikan sebesar 12 mmHg dan detak jantung 6,46 bpm.
Kuswandi (2008) yang mengatakan bahwa relaksasi dapat menurunkan kadar gula darah pada penderita diabetes mellitus. Relaksasi diketahui dapat membantu menurunkan kadar gula darah pada pasien diabetes melitus karena dapat menekan pengeluaran hormon-hormon yang dapat meningkatkan kadar gula darah, yaitu epinefrin, kortisol, glukagon, ACTH, kortikosteroid dan tiroid (Smetlzer et al, 2008).

Tai chi juga merupakan salah satu senam aerobik, dalam penelitian Indriyani dkk (2007) mengatakan senam aerobik berpengaruh terhadap penurunan kadar gula darah pada penderita DM tipe 2. Hasil penelitian menunjukan bahwa ada pengaruh latihan fisik senam aerobik terhadap penurunan kadar gula darah pada penderita DM tipe 2 di Wilayah Puskesmas Bukateja penurunan rata - rata sebesar $30,14 \mathrm{mg} \%$.

Tai Chi merupakan low impact exercise program yang termasuk dalam latihan aerobik, breathing exercise dan relaksasi untuk membantu mencegah dan meningkatkan kontrol diabetes. Penelitian ini sesuai dengan hasil penelitian yang menyatakan bahwa kadar glukosa darah puasa pada kelompok intervensi setelah senam tai chi mengalami penurunan yang signifikan. Pasien diabetes melitus dianjurkan untuk melakukan olahraga /latihan jasmani secara rutin (3-4 kali seminggu) selama kurang lebih 30 menit. Latihan ini bersifat CRIPE (continuous, rhythmical, interval, progressive, endurance training) (Waspadji, 2009).

Dalam penelitian ini senam tai chi memang cukup efektif dalam menurunkan kadar gula darah pada kelompok perlakuan dibandingkan dengan kelompok kontrol yang menunjukkan peningkatan pada kadar gula darah. Faktor yang mempengaruhi diantaranya adalah usia, pola hidup, diet gizi serta motivasi dari para responden. Pemberian senam tai chi bertujuan untuk menurunkan kadar gula darah melalui penekanan tingkat stress, gerakan aerobik serta meningkatkan rasa bahagia atau relaks 
pada responden (Nusantoro, 2016; Kuswandi, 2008; Indriyani dkk, 2007).

Latihan Tai Chi merupakan fewlow-felocity dan low impact exercise programs, yang mempunyai manfaat tinggi bagi lansia dan dapat dilakukan di mana saja. Latihan Tai Chi merupakan latihan tradisional dari cina yang menggabungkan latihan pernafasan, rileksasi, dan struktur gerakan yang pelan dan lembut (Srisurini 2003 dalam Supriani 2010).

Gerakan Tai Chi yang meliputi body-mind-soul-breath secara teratur terbukti dapat meningkatkan pelepasan non adrenalin melalui urin, menurunkan kadar cortisol, serta menurunkan aktivitas saraf simpatis yang membawa dampak positif pada jantung (berupa denyut jantung yang stabil dan tekanan darah turun menuju normal). Ini karena aktivitas saraf simpatis dan parasimpatis menjadi seimbang dan harmonis. Latihan tersebut dapat pula meningkatkan antioksidan untuk menghilangkan radikal bebas dalam tubuh dan menstabilkan tekanan darah dan kualitas tidur (Sutanto, 2013).

Senam Tai Chi adalah olah raga tradisional Cina dengan gerakan lambat, pernafasan yang dalam, dan pemusatan pikiran dengan unsur meditasi. Senam Tai Chi dikenal dapat membantu mengendalikan stress yang merupakan salah satu faktor risiko hipertensi dengan cara latihan pernafasan yang tepat dikombinasikan dengan latihan otot ringan sehingga membuat seseorang menjadi rileks. Teknik pernafasan yang dalam dan gerakan yang lambat dapat meningkatkan konsentrasi oksigen di dalam darah, memperlancar aliran darah, dan menurunkan denyut jantung (Istifa, 2011).

Studi yang dilakukan Razei et al (2011) Penelitian ini mengambil sampel 62 lansia berusia diatas 65 tahun. Kemudian dibagi menjadi dua kelompok yaitu kelompok latihan Tai Chi dan kelompok kontrol tidur. Latihan Tai Chi dilakukan sebanyak tiga sesi per minggu. Hasil penelitian menunjukan bahwa terjadi peningkatan kualitas tidur pada kelompok
Tai Chi yang diketahui dari pengurangan skor rata-rata PSQI tetapi tetap dalam karateristik kualitas tidur yang buruk sedangkan pada kelompok kontrol tidur tidak terjadi perubahan kualitas tidur yang signifikan.

Menurut Supriani 2010 senam Tai Chi dapat menurunkan aktivitas saraf simpatis yang membawa dampak positif pada jantung (berupa denyut jantung yang stabil dan tekanan darah turun menuju normal). Ini karena aktivitas saraf simpatis dan parasimpatis menjadi seimbang dan harmonis. Apabila dilakukan 3 kali seminggu dalam waktu satu bulan.

Dari hasil Analisa uji hipotesa diata dapat disimpulkan bahwa (1) Tai chi efektif menurukan tekanan darah pada lansia penderita hipertensi; (2) Tai chi efektif menurunkan kadar gula darah pada lansia penderita diabetes mellitus ; (3) Tai chi efektif meningkatkan kulaitas tidur pada lansia yang mengalami gangguan kualitas tidur.

\section{REFERENCES}

Adenikheir, A. 2014. Pengaruh Pemberian Senam Tai Chi Terhadap Peningkatan Kapasitas Vital Paru Pada Lanjut Usia. Skripsi. Universitas Muhammadiyah Surakarta.

Adib, M. (2011). Pengetahuan Praktis Ragam Penyakit Mematikan yang Paling Sering Menyerang Kita. Jogjakarta: Buku Biru

Bustan M.N.. (2007). Epidemiologi Penyakit Tidak Menular. Jakarta: PT. Rineka Cipta.

Florencia Jessica. (2015). Wanita Bekerja Lebih Berisiko Diabetes. https://diabetessolution.co.id/id/Artic le/View/70?slug=wanita-bekerjalebih-berisiko-diabetes, diakses 29 Mei 2017

Ghaderian N, Noushin MF, Firoozeh s, Gholam HS, Ali M, Maryam M. Is there any relationship between the type of dietary fat and blood glucose? Results of isfahan healthy heart program. Arya Atherosclerosis 
Journal. 2007 ; 3(3) ; 162-7

Giriwijoyo, S., \& Sidik, DZ. (2012). Ilmu

Kesehatan Olahraga. Bandung; PT

Remaja Rosdakarya

Gunawan, L. (2006). Hipertensi Tekanan Darah Tinggi. Yogyakarta; Kanisius.

Irwan. (2008). Mengenal Usia Lanjut dan

Perawatannya. Jakarta. Salemba Medika

Ismiati, I. 2013. Pengaruh Senam Otak dan

Senam Tai Chi Terhadap

Keseimbangan Lanjut Usia di

Posyandu Desa Gawang Pacitan.

Skripsi. Universitas Muhammadiyah

Surakarta.

Isselbcher, Braunwald, Wilson, Martin,

Fauci, Kasper. 2015. Horison :

Prinsip-Prinsip Ilmu Penyakit Dalam.

Jakarta. Buku Kedokteran EGC

Khasanah, Khusnul dan Hidayati, Wahyu.

2012. Kualitas Tidur Lansia Balai

Rehabilitasi Sosial "MANDIRI"

Semarang. Jurnal Nursing Studies.

No.1,Vol.1,Page.189-196.

LeeFever Joyce, (2007). Buku saku pemeriksaan laboratorium dan diagnostik dengan implikasi keperawatan. Edisi 2. Jakarta:EGC

Maas, L. Meridian. 2011. Asuhan Keperawatan Geriatric: Diagnosis NANDA, Kriteria Hasil NOC, Intervensi NIC. Jakarta: EGC.

Mahardika, J., Haryanto J., dan Bakar A. 2011. Hubungan Keteraturan Mengikuti Senam Lansia Dan Kebutuhan Tidur Lansia di UPT Pslu Pasuruan Di Babat Lamongan. Skripsi: Universitas Airlangga

Martinus. (2005). 1001 Tentang Diabetes. Bandung: Nexx Media

Maryam, RS., Ekasari, MF., Rosidawati., Jubaedi, A., \& Batubara, I. (2008). Mengenal Usia Lanjut dan Perawatannya. Jakarta; Salemba Medika.

Modjod, D. 2007. Insomnia Experience, Management Strategies, and Outcomes in ESDR Patient Undergoing Hemodialysis. Skripsi: Mahidol University.
Palmer, A. Williams, B. 2007. Simple guide

Tekanan Darah Tinggi. Ciracas, Jakarta; penerbit erlangga.

Permatasari Yulia Indah (2015). Pengaruh Senam Bugar Lansia Indonesia Terhadap Penurunan Kadar Gula Darah Pada Wanita Lansia. Skripsi : Universitas Negeri Semarang

Potter, P.A. dan Perry, A.G. 2005. Buku Ajar Fundamental Keperawatan: Konsep, Proses, dan Praktik (Volume 2) (Edisi 4). Jakarta: EGC.

Pudjiastuti, SR., \& Utomo, B. (2003). Fisioterapi pada Lansia. Jakarta ; EGC.

Radiah. 2015. Pengaruh Pemberian Expressive Movement Music Modality Therapy Terhadap Penurunan Tingkat Depresi Pada Lansia di Rumah Asuh Anak \& Lansia (RAAL) Griya Asih Lawang Kabupaten Malang. Skripsi: Universitas Muhammadiyah Malang.

Razei, A., Hosseini, H., Esfirizi, M., dan Marandi, S., 2011. The Effect of Tai Chi exercise on the Sleep Quality of the Elderly Residents in Isfahan. Sedeghieh Elderly Home. No.1,Vol.16,Page.55.

Rohmaningsih, Novitasari dan Fitrikasari, Alifiati. 2013. Hubungan antara Kualitas Tidur dengan Tingkat Kecemasan Studi pada Mahasiswa/i Angkatan 2011 Program Studi Pendidikan Dokter Fakultas Kedokteran Universitas Diponegoro. KTI: Universitas Dipenogoro.

Roth, Thomas. 2007. Insomnia: Definition, Prevalence, Etiology, and Consequences. Journal of Clinical Sleep Medicine. No.5, Vol.3,Page.7.

Safitri Viska, (2012). Perubahan Hormon ketika Menopause. http://viskhasafitri.blogspot.co.id/201 2/06/perubahan-hormon-ketikamenopause.html, Diunduh 28 Maret 2017

Santoso, D. (2010). Membonsai Hipertensi. Surabaya; jaring pena

Shadine, Mahannad. 2010. Mengenal 
Penyakit Hipertensi, Diabetes, Stroke \& Serangan Jantung. Jakarta. KEENBOOK

Siyad, AR. 2011. Hypertension. Hygeia: Journal For Drugs And Medicines. No.1. Vol.3.Page 1-16.

Soegondo,S. (2007). Diagnosis dan Kalsifikasi Diabetes Mellitus Terkini. Dalam Soegondo S dkk (eds), Penatalaksanaan Diabetes Mellitus Terpadu. Jakarta : FKUI.

Sudoyo AW, Setiyohadi B, Alwi I, K Marcellus S, Setiati S. (2006). Buku Ajar Ilmu Penyakit Dalam Jilid III Edisi Keempat. Jakarta: FKUI.

Sudoyo AW, Setiyohadi B, Alwi I, K Marcellus S, Setiati S. (2006). Buku Ajar Ilmu Penyakit Dalam Jilid III Edisi Keempat. Jakarta: FKUI.

Sutanto, Jusuf. 2013. The Dancing Leader 3.0 Tai Chi untuk Perawat Membangun Keluarga dan Rumah Sakit. Jakarta : PT Kompas Media Nusantara.

Yuliati Amalia , Baroya Ni'mal, Ririanty Mury, (2014). Perbedaan Kualitas Hidup Lansia yang Tinggal di Komunitas dengan di Pelayanan Sosial Lanjut Usia. e-Jurnal Pustaka Kesehatan, vol. 2 (no. 1)

Sari, S. P. (2016). Upaya Meningkatkan Keterampilan Motorik Kasar Melalui Senam Irama Pada Anak Kelompok A Tk Pertiwi 21.1 Setda Kabupaten Sragen, (September).

Utami, N. A. (2017). Hubungan Pola Makan Dan Aktivitas Fisik Terhadap Kejadian Overweight Dan Obesitas Pada Remaja. Pendidikan, Program Kedokteran, Sarjana Kedokteran, Fakultas Diponegoro, Universitas.

Warhamny, W., Laenggeng, A. H., \& Moonti, S. W. (2018). Hubungan Pola Makan Dan Aktivitas Fisik Dengan Kejadian Obesitas Pada Anak Balita Di Kelurahan Lolu Selatan Wilayah Kerja Puskesmas Birobuli Kota Palu. Jurnal Kolaboratif Sains, Universitas Uhammadiyah Palu, 1(1), 736-744. 